\title{
Meridional equatorial electrojet current in the American sector
}

\author{
R. G. Rastogi \\ INSA Senior Scientist, Gujarat University, Ahmedabad 380009 Visiting Scientist Physical Research Laboratory, Ahmedabad
}

Received: 19 February 1998 / Revised: 4 June 1998 / Accepted: 23 June 1998

\begin{abstract}
Huancayo is the only equatorial electrojet station where the daytime increase of horizontal geomagnetic field $(H)$ is associated with a simultaneous increase of eastward geomagnetic field $(Y)$. It is shown that during the counter electrojet period when $\Delta H$ is negative, $\Delta Y$ also becomes negative. Thus, the diurnal variation of $\Delta Y$ at equatorial latitudes is suggested to be a constituent part of the equatorial electrojet current system. Solar flares are known to increase the $H$ field at an equatorial station during normal electrojet conditions (nej). At Huancayo, situated north of the magnetic equator, the solar flare effect, during nej, consists of positive impulses in $H$ and $Y$ and negative impulse in $Z$ field. During counter electrojet periods (cej), a solar flare produces a negative impulse in $H$ and $Y$ and a positive impulse in $Z$ at Huancayo. It is concluded that both the zonal and meridional components of the equatorial electrojet in American longitudes, as in Indian longitudes, flows in the same, E region of the ionosphere.
\end{abstract}

Key words. Geomagnetism and paleomagnetism (dynamo theories) - Ionosphere (equatorial ionosphere; ionosphere disturbances)

\section{Introduction}

Since the discovery of the equatorial electrojet (Egedal, 1947; Chapman, 1951) the horizontal field $H$ at low latitudes has been studied by numerous scientists. Chapman and Rajarao (1965) identified the semi-annual variations of the $H$ and $Z$ fields as the characteristics of a station within the equatorial electrojet belt. The study of the eastward field, $Y$, at low latitudes has been almost neglected to date. Forbush and Casaverde (1961) described the daily and latitudinal profiles of $\Delta H, \Delta Y$, and $\Delta Z$ at equatorial stations in Peru on some selected days of IGY. A positive excursion of $\Delta H$ during the day was shown to be associated with negative excursion of $\Delta Z$ and positive excursion of $\Delta Y$. Price and Stone (1964) showed $X, Y$ and $Z$ variations at several low latitude stations during IGY.

While studying the daily variation of $H, Y$ and $Z$ at the Indo-USSR chain of stations, Patil et al. (1983) found that the daily variations of $\Delta Y$ at equatorial stations in India showed distinct midday depression opposite to that of $\Delta H$. Rastogi (1993) showed a very systematic daily, seasonal and solar cycle variation in $Y$ field at Kodaikanal. Rastogi and Verma (1994) have shown that in the Indian sector the eastward zonal current (positive $\Delta H$ ) due to normal electrojet is associated with a poleward meridional current (negative $\Delta Y$ ). During periods of counter electrojet (westward zonal current, negative $\Delta H$ ), the meridional current is reversed to the equatorial direction, positive $\Delta Y$ ). Thus, the meridional current at equatorial latitudes in India was considered as an integral part of the zonal electrojet current and not entirely a global current system of interhemispherical field-aligned current. Rastogi (1996) examined the effects of solar flare on $Y, H$ and $Z$ fields at the equatorial electrojet station, Annamalainagar. It was shown that during the periods of normal electrojet (positive $\Delta H$ ) the solar flare effect was positive in $H$ and negative in $Y$ and $Z$ fields, while during the counter electrojet period the negative excursion of $H$ was accompanied by positive excursions in $Y$ and $Z$ fields. Thus, it was concluded that both the zonal and meridional current in Indian longitudes flow in the same $\mathrm{E}$ region of the ionosphere.

Rastogi and Stening (1997 submitted) showed that the annual mean daily variation of $Y$ field at equatorial latitudes differs appreciably with longitude. Whereas, $\Delta Y$ at Trivandrum shows a significant midday minimum, the same at Huancayo shows a large midday maximum. At other stations $\Delta Y$ is minimum at noon and maximum in the morning or the evening hours. In this study, this seemingly anomalous variation of $\Delta Y$ at Huancayo is examined during normal electrojet, counter 
electrojet and solar flare periods. The results described herein are based on the examination of the magnetograms at Huancayo for the period 1948 to 1976. Before discussing the analysis the coordinates of Huancayo (HUA) are described.

Geographic coordinate $12.1^{\circ} \mathrm{S}, 75.3^{\circ} \mathrm{W}$

Geomagnetic coordinate $-0.8^{\circ}, 355.2^{\circ}$

Horizontal field, $H$

29171 nT (1948), 28424 nT (1961)

Declination, $D$ $6^{\circ} 17.0^{\circ} \mathrm{E}(1948) 5^{\circ} 01.4^{\prime}(1961)$

Vertical field, $Z$ 1046 nT (1948) 1025 nT (1961)

Inclination, $I$ $2^{\circ} 03.26^{\prime}(1948) 2^{\circ} 03.99^{\prime}(1961)$

Speed of magnetograms

$20 \mathrm{~mm}$ per hour

Sensitivity of $D$ trace

$1.0^{\prime} / \mathrm{mm}$ or $8 \mathrm{nT} / \mathrm{mm}$

Sensitivity of $H$ trace

$3.5 \mathrm{nT} / \mathrm{mm}$ (1948-1952 August)

$17.2 \mathrm{nT} / \mathrm{mm}$ (1952 August-1957 October)

$3.5 \mathrm{nT} / \mathrm{mm}$ (1957 October-1961)

Sensitivity of $Z$ trace

\section{3-3.5 nT/mm (1948-1961)}

This information could be utilised to check the excursions of the $H, Y$ and $Z$ traces in the magnetograms reproduced here.

In Fig. 1 are shown the annual mean daily variations of the eastward field, $Y$, at the equatorial electrojet stations at different longitudes for year 1958. At Kodaikanal (KOD) the mean daily variation consisted of mainly a single minimum around noon. At other stations, Ibadan (IBD), Addis-Ababa (AAE), Koror (KOR) and Jarvis (JAR) the midday minimum was present but minor maxima were seen in the morning and evening hours. At Huancayo (HUA) a prominent maximum of $\Delta Y$ exceeding $40 \mathrm{nT}$ was seen around noon. This, seemingly anomalous, behaviour of $\Delta Y$ at Huancayo is not seen at any other equatorial station. This has led the author to investigate the daily mean behaviour and solar flare effects in $\Delta Y$ at Huancayo during eastward and westward electrojet current periods.

In Fig. 2 are shown the mean daily variations of $H, Y$ and $Z$ fields at Huancayo for three Lloyd seasons $\mathrm{J}$ months consisting of May, June, July and August, Emonths consisting of March, April, September and October and D-months consisting of November, December, January and February months and for the annual mean for the low sunspot years 1954-55 and the high sunspot year 1957-58. The daily variations of $H$ have been consistently similar during any of the seasons with a maximum at or shortly before noon, the magnitude being larger during 1957-58 than during 1954-55. The $Z$ field showed a minor maximum near sunrise and a pronounced minimum around $1500 \mathrm{~h}$, whose amplitude was larger in 1957-58 than in 1954-55.

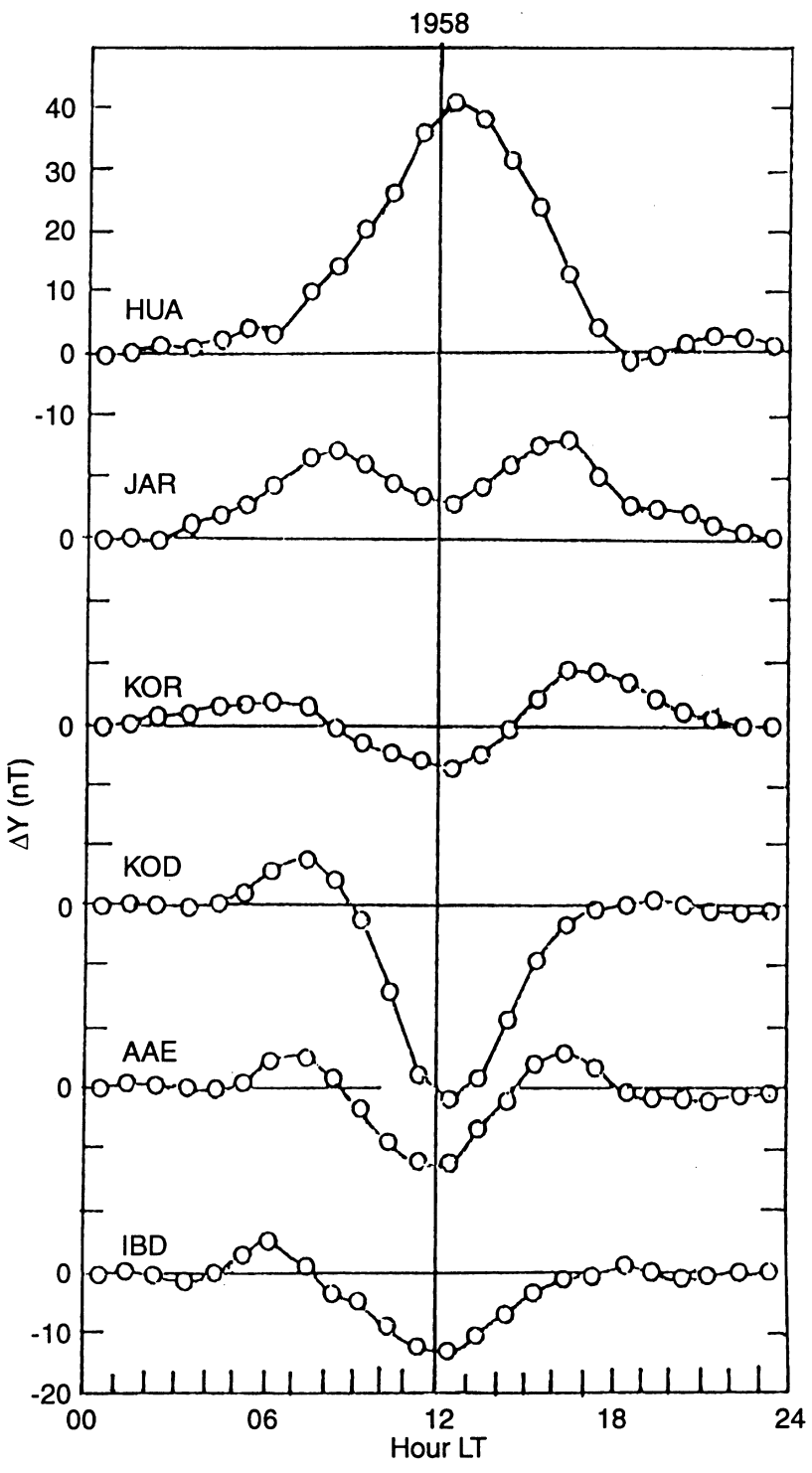

Fig. 1. Mean yearly solar daily variations of eastward components of geomagnetic field, $Y$, at the equatorial stations. Ibadan (IBD), AddisAbaba $(A A E)$, Kodaikanal $(K O D)$ Koror $(K O R)$, Jarvis $(J A R)$ and Huancayo $(H U A)$ during 1958

The daily variation of $Y$ field during J-months (local winter) showed a maximum around $0600 \mathrm{~h}$, followed by a dip at $10-11 \mathrm{~h}$ and another maximum around $1300 \mathrm{~h}$. During E-months the morning peak of $Y$ decreased and the midday peak increased in amplitude compared to that during J-months. During the D-months (local summer) a very prominent peak was observed at midday with minor minima around sunrise and sunset period. The amplitude of daily variations of $Y$ were larger in 1957-58 than 1954-55. The variations of $Y$ field in American longitudes are very different from the corresponding variations in Indian longitudes which were earlier described by Rastogi (1993).

Figure 3a shows relationship of midday and midnight values of $H$ at Huancayo in relationship with the corresponding daily range $H$ during January-February, 

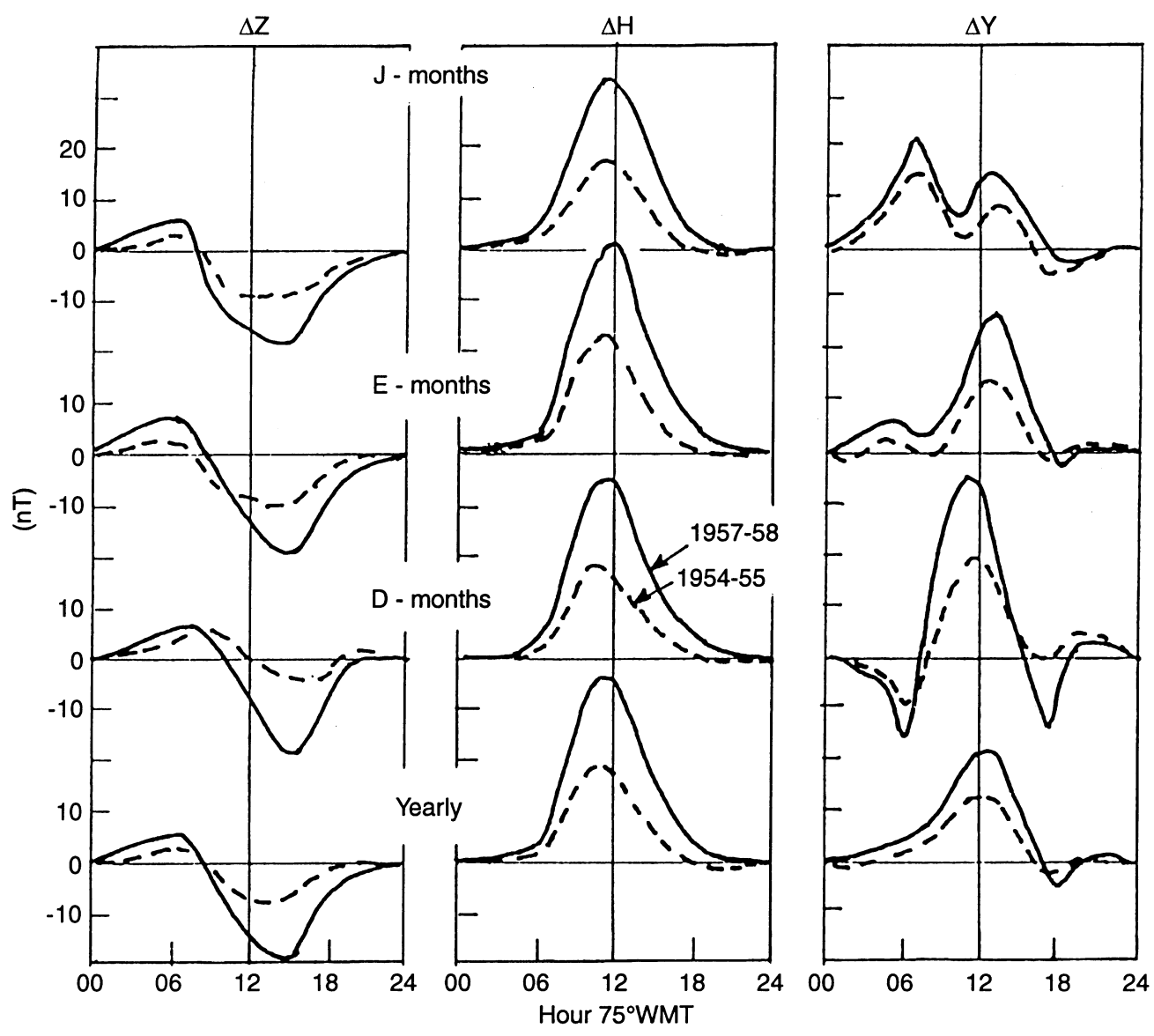

Fig. 2. Solar daily variations of $H, Y$ and $Z$ fields at Huancayo averaged for different Lloyd seasons of low sunspot years (1954-55) and high sunspot years $(1957-58)$
1958. As well known the day-to-day variations in the daily range of $H$ is contributed mainly by the corresponding variations of the midday values of $H$, while the midnight value of $H$ remains practically constant.

Figure $3 \mathrm{~b}$ showing relationship of midday and midnight values of declination $D$ with the daily range of $\mathrm{D}$ also indicates that the day to day variations of $\mathrm{D}$ is also mainly due to corresponding variations of the midday values of D. Figure 3c shows the relationship between daily range of $Y$ in relation with the daily range of $H$. In spite of some scatter of points, it can be concluded that the range of $D$ increases in unison with the increase of range of $H$. Thus, it is concluded that the daily variations of $H$ as well as $D$ at Huancayo are the daytime phenomena and are closely related with each other varying in unison from day to day.

The hourly values of $\Delta H$ and $\Delta Y$ at different hours can be combined to show the direction of magnetic vector which when turned by $90^{\circ}$ gives the direction of current vector. In Fig. 4 are shown the variations of direction and magnitude of current vectors during the day of different seasons of the year. It is seen that the current vector at Huancayo, in general, is inclined by about $7^{\circ}$ south of east. Thus, the ratio of $\Delta Y / \Delta H$ at Huancayo was about $1 / 8$ on the average.

Along Indian sector the direction of $H, Y$ and $Z$ fields are reversed during the counter electrojet period, so we next examined the magnetograms at Huancayo during counter electrojet events. In Fig. 5 are shown some magnetograms indicating either morning or afternoon cej conditions. On November 8, 1975 (Fig. 5a) the $H$ field around 12 UT (07 LT) had fallen below the base nighttime value. This was accompanied by an increase of $Z$ field and the decrease of the $D$ (or $Y$ ) field. Similarly on October 14, 1975 (Fig. 5b) the decrease or $H$ below base midnight value in the morning hours was accompanied by a decrease of $Y$ and an increase of $Z$ field. On December 21, 1975 (Fig. 5c) there was a distinct afternoon counter electrojet around 19-20 UT (14-15 LT) which was accompanied with decrease of $D$ and increase of $Z$ field. On November 28, 1977, (Fig. 5d) a very strong counter electrojet occurred between 16-17 UT (11-12 LT) which was associated with decrease of $D$ and increase of $Z$. Thus it is seen that during the reversal of $\Delta H$, the signs of $\Delta Y$ and $\Delta Z$ are also reversed with respect to normal.

In Fig. 6 are shown two cases of counter electrojet events in comparison with the corresponding normal Sq variations: On September 25, 1955 there was a cej around $09 \mathrm{LT}$, and it can be seen that $\Delta Y$ during the corresponding period showed a minimum while $\Delta Z$ showed a maximum. On Jan 11, 1951 a strong cej occurred in the afternoon around $15 \mathrm{LT}$. The $\Delta Y$ showed a prominent minimum during the same period while $\Delta Z$ showed a definite maximum.

It is concluded that in American longitudes too, as in Indian longitudes, the changes in $\Delta Y, \Delta H$ and $\Delta Z$ during 

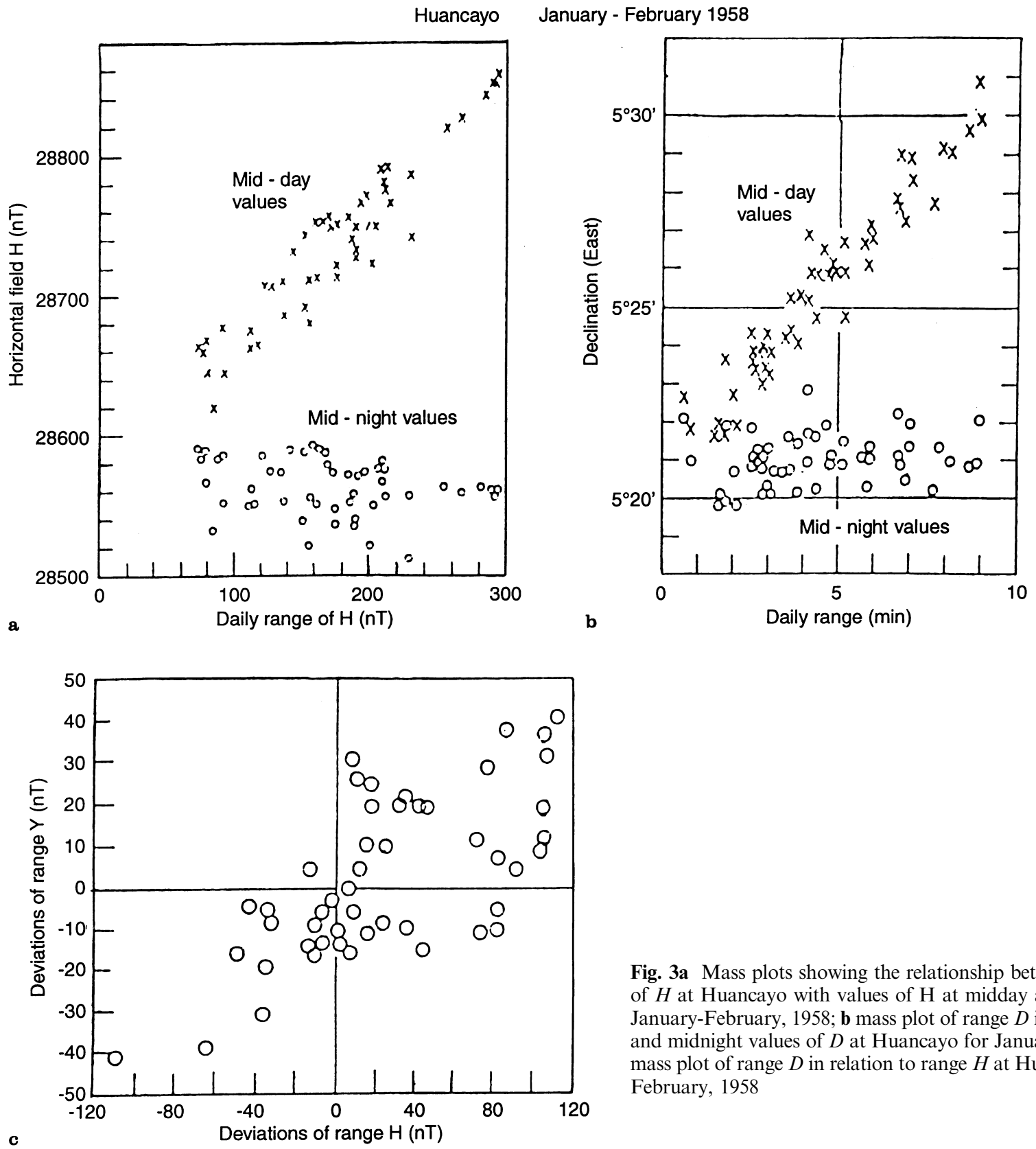

Fig. 3a Mass plots showing the relationship between the daily range of $H$ at Huancayo with values of $\mathrm{H}$ at midday and midnight during January-February, 1958; b mass plot of range $D$ in relation to midday and midnight values of $D$ at Huancayo for January-February 1958; c mass plot of range $D$ in relation to range $H$ at Huancayo for JanuaryFebruary, 1958

counter electrojet periods are reversed to those during normal electrojet period. In other sense the eastward electrojet in American sector produces a positive $\Delta H$ and $\Delta Y$ but a negative $\Delta Z$. During the counter electrojet period $\Delta H$ and $\Delta Y$ have negative excursion while $\Delta Z$ has a positive excursion.

Next we examine the effect of solar flares on the $D, H$ and $Z$ components of the geomagnetic field at Huancayo.

First in Fig. 7 a diagram from a paper by Nagata (1952) is reproduced. It shows tracings of $D, H$ and $Z$ fields during a solar flare on September 6, 1939. It is seen that the excursions in $H$ trace are very prominent but the same in $D$ and $Z$ are very small. This is due to the sensitivity of $D$ trace $(8 \mathrm{nT} / \mathrm{mm})$ being lower than that of $H$ trace $(3.5 \mathrm{nT} / \mathrm{mm})$ besides which the normal

variations of $D$ are always smaller than the corresponding variation of the $H$ field average ratio of $\Delta Y / \Delta H$ being $1 / 8$. While surveying the magnetograms for solar flare effects (sfe), many of the cases when the excursions in $H$ were clear but the excursions in $Y$ fields were too small to measure precisely. The solar flare of September 6, 1939 produced a positive excursion in $H$ and $Y$ fields and a negative excursion in $Z$ field.

In Fig. 8a the magnetograms associated with sfe at 1441 UT (0941 LT) on Feb 13, 1956 and at 1622 UT (1122 LT) on March 15, 1956 are shown. In Fig. 8b are shown the variations of $\Delta H, \Delta Y$ and $\Delta Z$ on these days compared with the corresponding monthly mean solar quiet day variation $(\mathrm{Sq})$. The $\mathrm{Sq}$ variations of $\Delta H$ and $\Delta Y$ shows a midday maxima and $\mathrm{Sq}(Z)$ shows a afternoon minimum, $\Delta Z$. The solar flare excursions in 


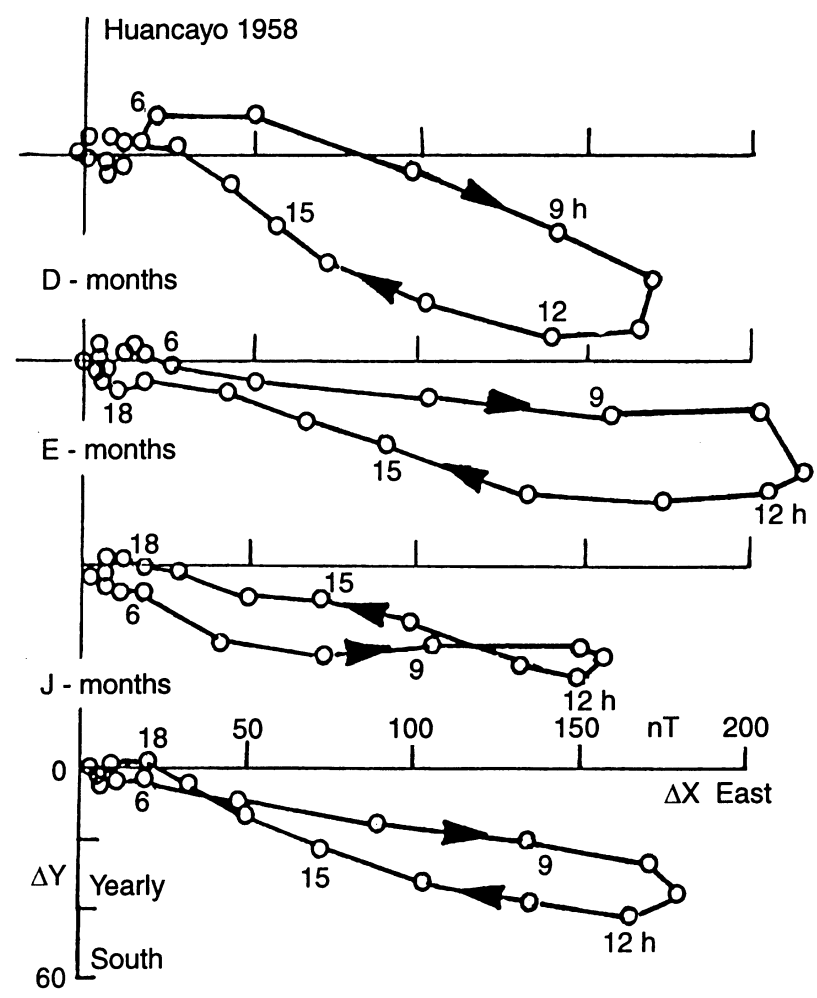

Fig. 4. The daily variations of the current vector at Huancayo during different seasons of 1958
$H$ trace were too large, such that the trace extended beyond of the recording paper. It is clearly seen that the excursions in $D$ were positive in both cases. The amplitudes of the crochet on February 13, 1956 were $120 \mathrm{nT}$ for $\mathrm{H}$ and $35 \mathrm{nT}$ for $Y$, the same on March 15, 1956 were $135 \mathrm{nT}$ for $H$ and $41 \mathrm{nT}$ for $Y$.

Solar flares have been associated with the absorption of radio waves resulting in the disappearance of radio echoes on vertical ionospheric sounding equipment. In Fig. 9 are shown the magnetogram and the ionospheric f-plot for February 27, 1967. The solar flare at 1641 UT (1141 LT) produced a large positive excursion in $H$ and a small impulse in $D$ field. The minimum frequency reflected from the ionosphere, f min, was $2.8 \mathrm{MHz}$ at $1130 \mathrm{LT}$, rose to $7.9 \mathrm{MHz}$ at $1145 \mathrm{LT}$. At $1200 \mathrm{LT}$ there was a complete blackout of the ionospheric echoes. The $\mathrm{f}$ min remained above normal up to $1300 \mathrm{LT}$.

Figure 10 shows the magnetograms and ionospheric f-plot at Huancayo on August 7, 1972 when an abnormally large solar flare occurred at 1513 UT (1013 LT). An increase of $D$ field is very clearly seen. In this case there was complete blackout of ionospheric echoes from $1015 \mathrm{LT}$ to $1100 \mathrm{LT}$. The absorption effects, with large values of $\mathrm{f}$ min were present up to $1500 \mathrm{LT}$.

Figure 11 shows the magnetogram and ionospheric $\mathrm{f}$ plot for October 20, 1957 when a solar flare occurred at 1644 UT or $1144 \mathrm{LT}$. The impulse of sfe is positive for $H$
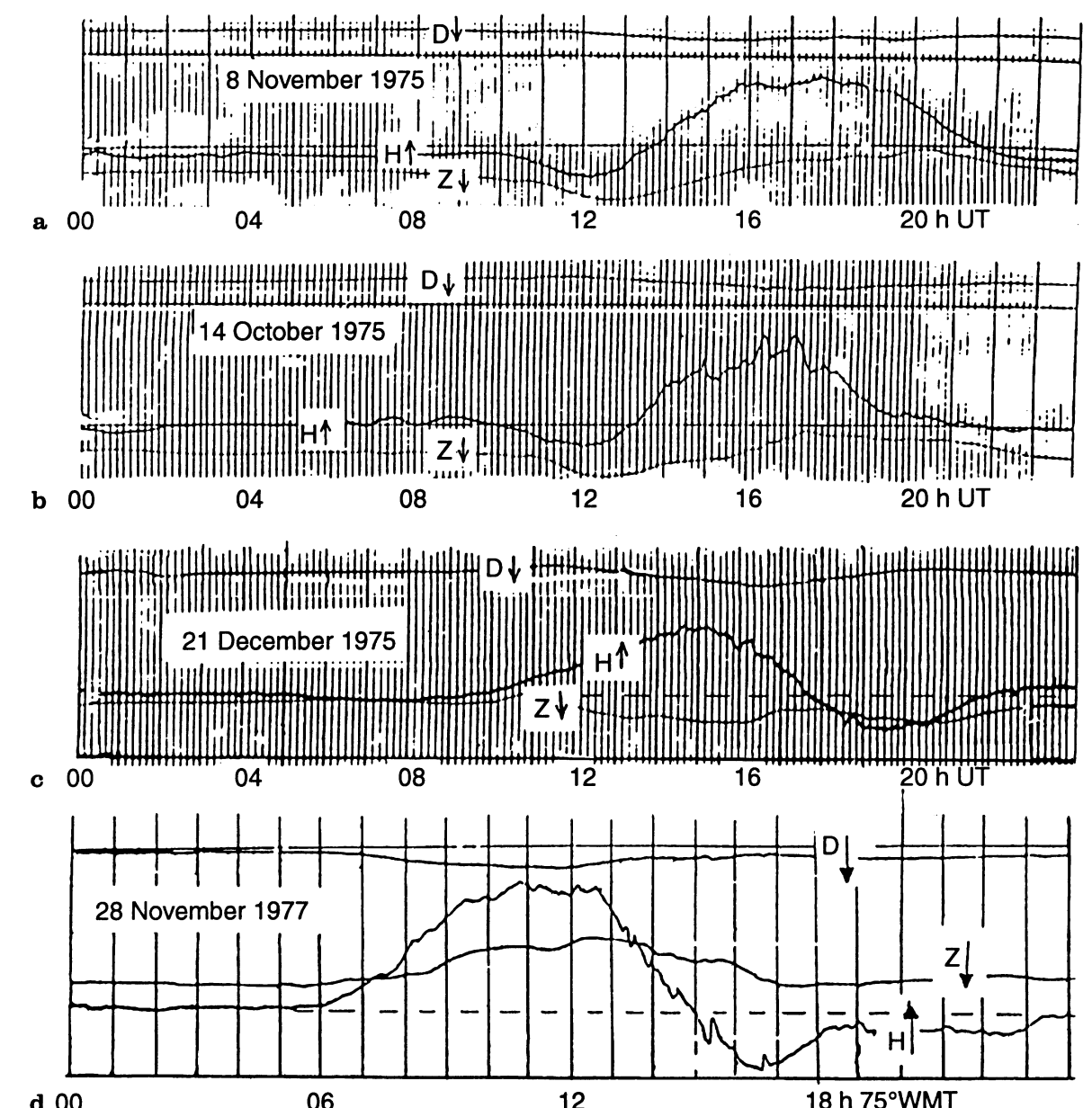

Fig. 5. Reproduction of the magnetograms at Huancayo on some days with a counter electrojet period 


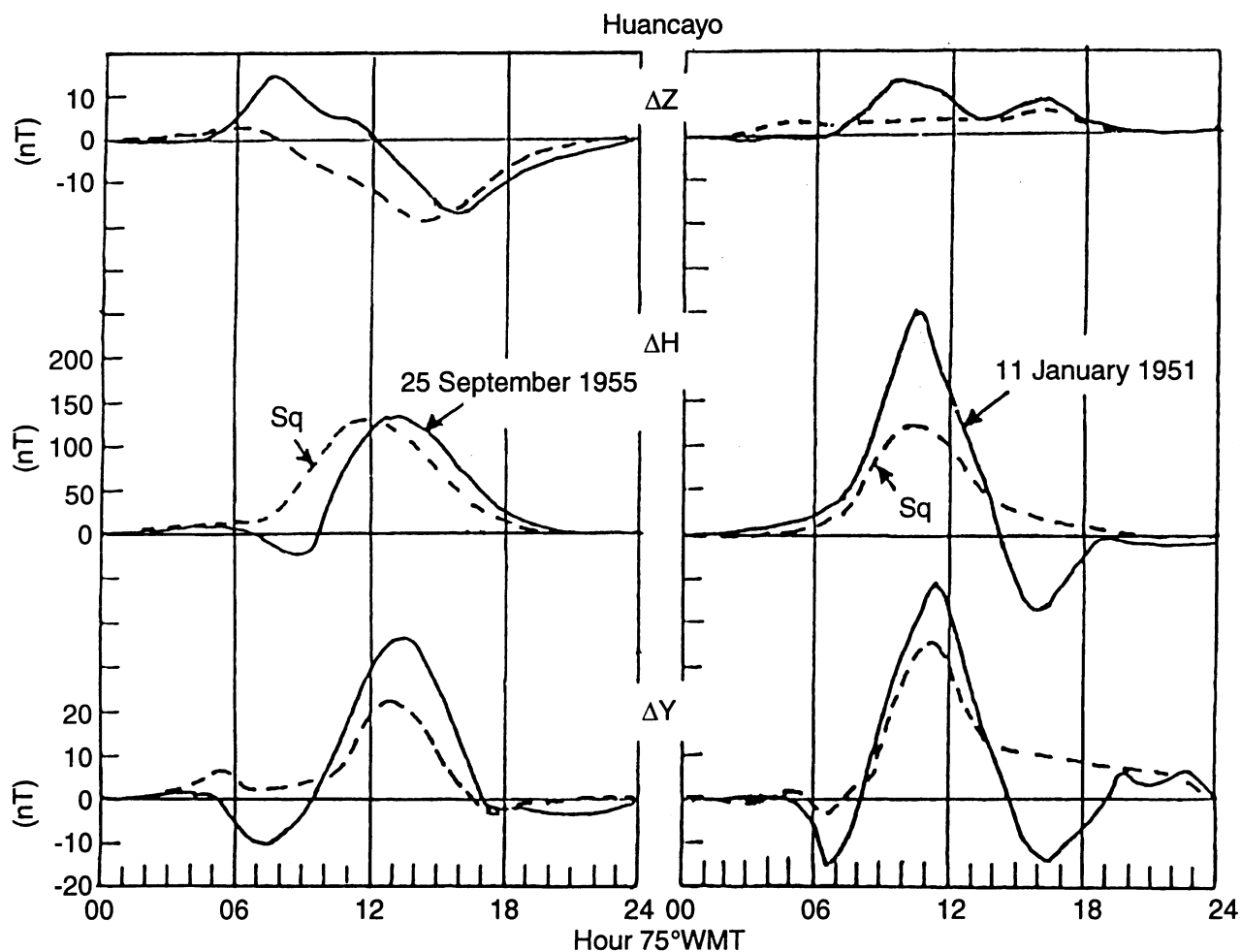

Fig. 6. Daily variations of $H, Y$ and $Z$ fields on counter electrojet days compared with corresponding $\mathrm{Sq}$ variations

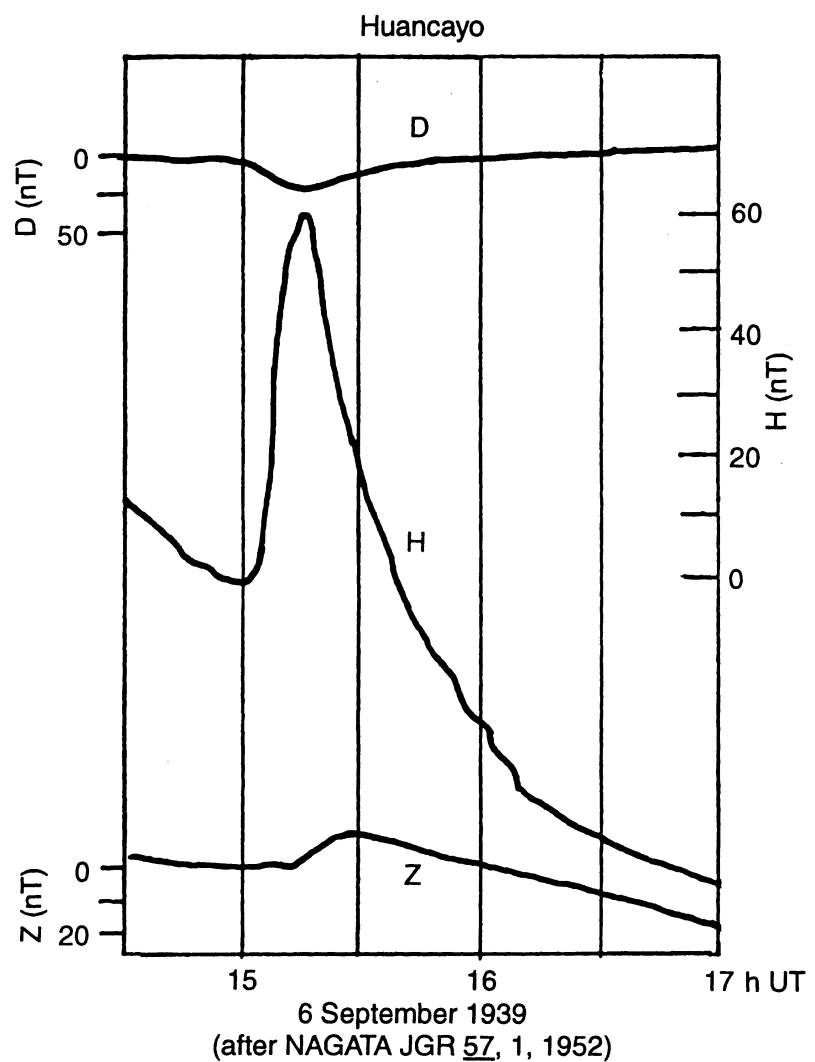

Fig. 7. Reproduction of magnetogram at Huancayo during the solar flare on September 6, 1939 (after Nagata, 1953)

and $D$ but negative for the $Z$ field. The flare was associated with a complete blackout of ionospheric echoes at 1206, 1215 and 1230 LT and the absorption effect persisted to about 1430 LT. This flare showed clearly the increase of $E$ region critical frequencies, foE, after the recovery from the blackout period.

Figure 12 shows the directions of current vectors at the onset and peak times of some of the flares. The ratio of flare vectors and $\mathrm{Sq}$ vectors are indicated respectively by $\mathrm{Sf}$ and So. It is seen that the directions of flare vectors are the same as those of $\mathrm{Sq}$ vector confirming that the flare effect is the enhancement of the Sq current just prior to the onset of the flare. In the columns are given the ratios of impulses during flare ( $H \mathrm{f}$ and $Y \mathrm{f}$ ) to the preflare deviations ( $H_{0}$ and $Y_{\mathrm{O}}$ ) for each flare. It is seen that the ratio of $H \mathrm{f} / H_{\mathrm{o}}$ and $Y \mathrm{f} / Y_{\mathrm{O}}$ for any particular flare are practically same even though, from one flare to another, it varied from 0.3 to 5.8 . This suggests that proportionately the same enhancement is observed in the zonal and meridional parts of the equatorial electrojet during a solar flare.

Finally, we examined solar flare effects during counter electrojet events. Some of these events are reproduced in the magnetograms in Fig. 13. It must be remembered that the counter electrojet events normally occur in the morning or evening hours where the deviations of $H$ field from its night time level is small. Hence the impulse in the $D$ trace would be too small to register due to its smaller magnitude and further by weaker sensitivity of the $D$ traces. On February 10, 1956 (Fig. 13a) a solar flare occurred at 2048 UT (1548 LT). The flare occurred in the local evening hour when $\Delta H$ had decreased below the night level and hence the sfe impulse in $H$ was also negative. A negative impulse in $D$ can also be identified. On October 9, 1961 a flare occurred during a cej event and a negative impulse in $H$ was associated with a positive impulse in $Z$, and a weak 

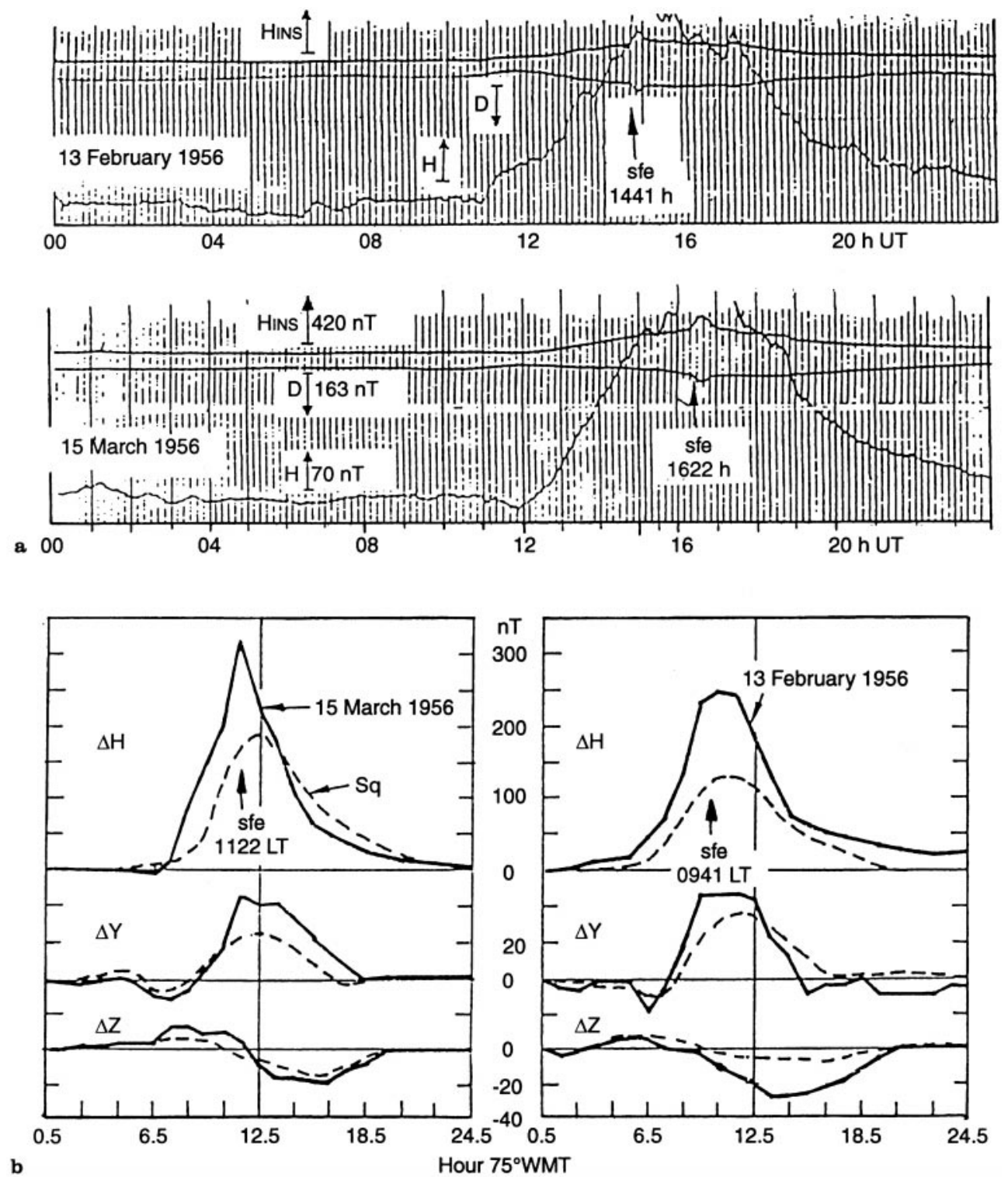

Fig. 8. a Reproductions of magnetograms at Huancayo during the solar flares on March 15, and February 13, 1956; b solar daily variations of $H, Y$, and $Z$ on March 15, and February 13, 1956 compared with corresponding monthly mean $\mathrm{Sq}$ variations. uncertain impulse in $D$. On April 9, 1961 a solar flare occurred at 1217 UT (0717 LT) in which a negative impulse in $H$ was accompanied by a negative impulse in $D$ field. On March 5, 1972 (Fig. 13d) three flares occurred at $0814 \mathrm{LT}, 1137 \mathrm{LT}$ and $1231 \mathrm{LT}$. It is interesting to note that the sfe at $0814 \mathrm{LT}$ produced a weak positive impulse when $\Delta H$ was just above nighttime value. Around $07 \mathrm{LT}$ the $H$ field had decreased below the night value and the impulses in $H$ field at 1137 and 1231 were negative. The amplitude in $H$ was small and so its effect on $D$ and $Z$ traces were not noticeable.

\section{Discussion}

The first regular geomagnetic observations over the magnetic equator were started at Trivandrum in India. Although only declination observations were taken, Broun (1874) produced remarkable set of original findings on the daily, seasonal, solar cycle and disturbed geomagnetic variations of declination. During the period November to February daily variations of $D$ was shown to be inverse to that between May to September, a fact almost completely forgotten since Brown's (1874) observations. Only very recently the importance of declination in equatorial and low latitude has been called. The first standard geomagnetic observatory within, the now known, equatorial electrojet belt was again established in India at Kodaikanal in 1902 by the Survey of India and it continued operation till 1923. It is only since the establishment of the geomagnetic observatory at Huancayo in 1922 and the reports by McNish (1937) that the abnormally large solar daily variation in $H$ at an equatorial station was realised by the scientific community. The collection of $\mathrm{Sq}(H)$ data at low latitudes then available lead Egedal (1947) to detect a narrow belt of large $\mathrm{Sq}(H)$ variation centered over the magnetic equator. It was the latitudinal survey of $\mathrm{Sq}(H)$ at 14 stations in Peru by A.A. Giesecke that finally confirmed a belt of $\pm 3^{\circ}$ magnetic latitudes of abnor- 

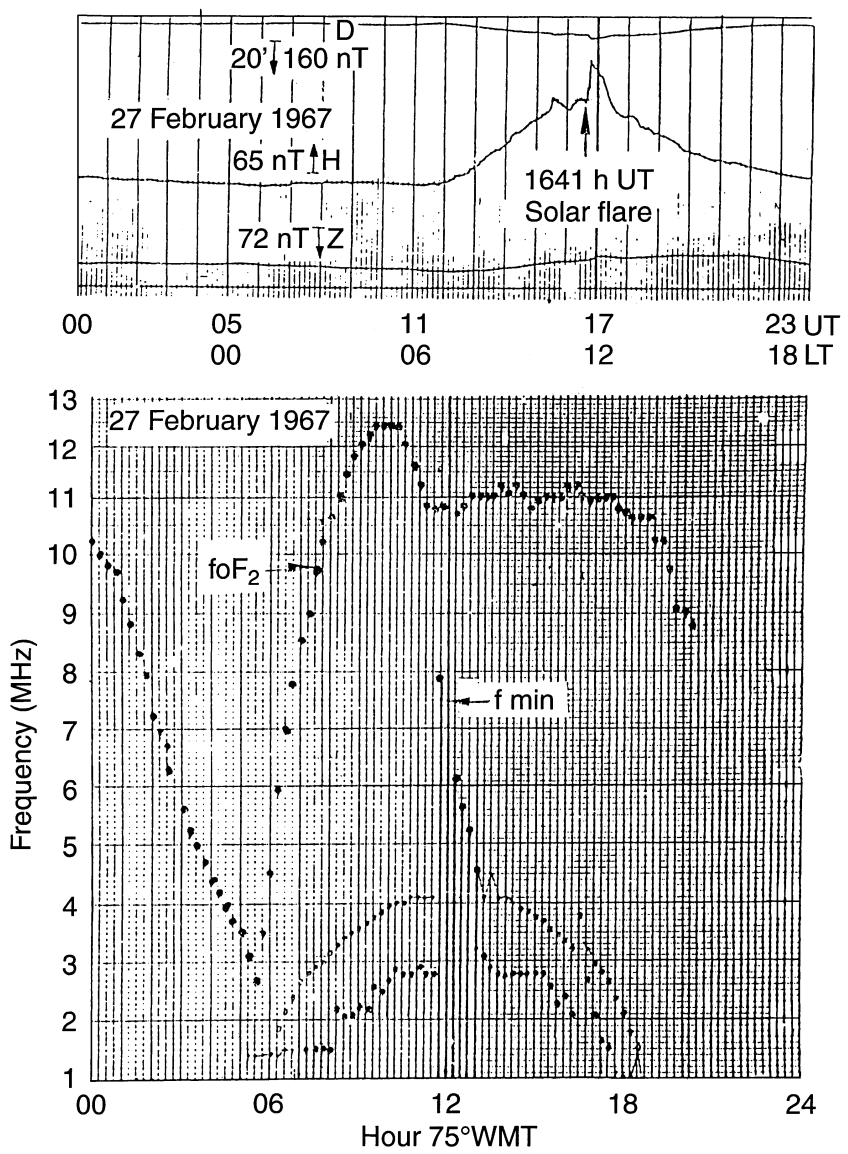

Fig. 9. Magnetograms and ionospheric f-plots at Huancayo associated with solar flare on February 27, 1967

mally large $\mathrm{Sq}(H)$ which Chapman (1951) attributed to a band of eastward current named the Equatorial Electrojet. Chapman (1951) gave the first model of the electrojet giving the latitudinal profiles of daily ranges of $H$ and $Z$. Chapman and Rajarao (1965) studied geomagnetic data at low latitudes taken during IGY period and characterised the electrojet stations by the equatorial maxima of the $\mathrm{Sq}(H)$ and $\mathrm{Sq}(Z)$ at these stations. So far no interest or mention had been paid to the daily variation of $\mathrm{Sq}(D)$ at electrojet stations. Price and Stone (1964) described and discussed the daily variations of all three components of the geomagnetic field at equatorial and low latitudes. Forbush and Casaverde (1961) were the first to examine to $D, H$, and $Z$ data at Peruvian stations with regards to daily variation, latitudinal variation, solar flare effects and sudden storm commencement signature. The importance of the declination data at Indian stations along with the $H$ and $Z$ data has been stressed by Rastogi $(1993,1994,1996)$. It has been clearly demonstrated that the variations of the $D$ field are intimately associated with the corresponding $H$ variations in the equatorial electrojet region of the Indian sector. It had been concluded that both the meridional and zonal currents are an integral part of the Equatorial Electrojet current superposed over the planetary Sq current system.
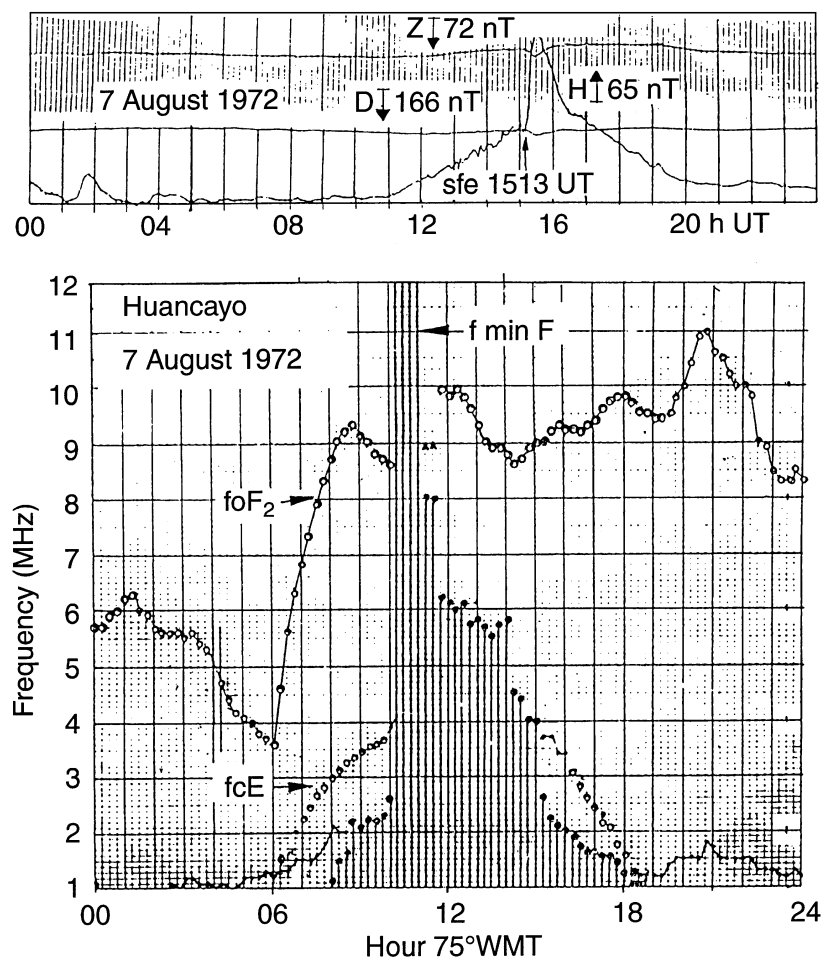

Fig. 10. Magnetograms and ionospheric f-plots at Huancayo associated with solar flare on August 7, 1972

The original Sq current system described by Bartels (Chapman and Bartels, 1940) assumed a constant value of $D$ and $Z$ over the magnetic equator throughout the day and basically represented the planetary Sq current system without any equatorial electrojet.

McNish (1937) included the data of Huancayo and showed a much stronger eastward current at low latitudes. Several analyses of the IGY data have been made to derive the ionospheric current system (Matsushita and Maeda, 1956; Parkinson, 1971; Malin and Gupta 1977), but all these models fail to reproduce the observed equatorial geomagnetic field variations (Suzuki, 1973).

The first and simplest model of the electrojet was given by Chapman (1951) according to which the $\Delta H$ should be maximum at the centre of the electrojet belt and $\Delta Z$ to be maximum (minimum) near the southern (northern) fringe of the belt. Suguira and Cain (1966) computed the two-dimensional current profiles for the longitudes of $80^{\circ} \mathrm{E}$ (India) and $280^{\circ} \mathrm{E}$ (Peru) and showed that the maximum current density in the electrojet is larger in the American than in the Indian longitudes, in conformity with the earlier observations of Rastogi (1992).

The previous models assumed complete inhibition of the vertical polarisation Hall current and thus the condition of divergence-free current was not satisfied (i.e. $\Delta \cdot J \neq 0$ ). Untiedt (1967) obtained a solution that satisfies the condition $(\nabla \cdot J=0)$ : his solution includes vertical currents and consequently a meridional current system resulting in a toroidal magnetic field which points towards magnetic west on the northern side of the 

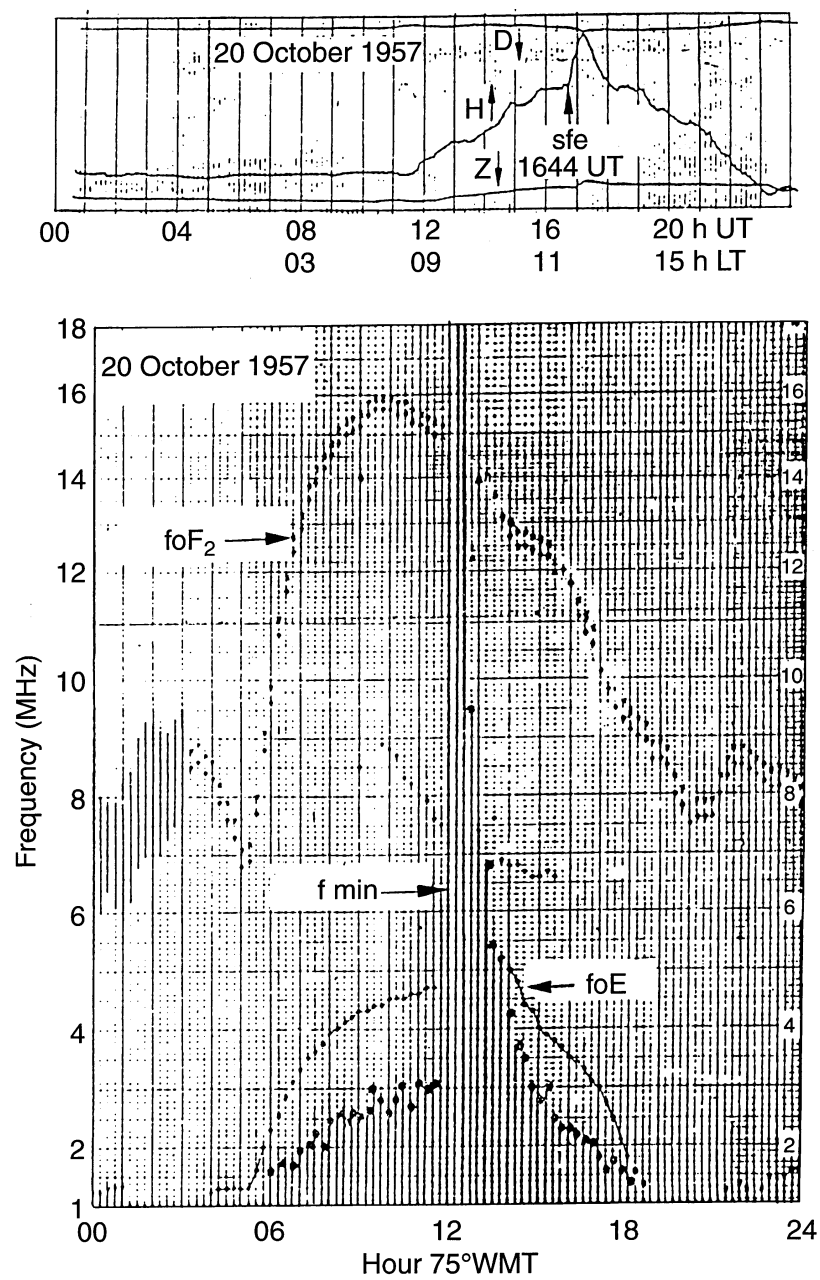

Fig. 11. Magnetograms and ionospheric f-plots at Huancayo associated with solar flare on October 20, 1957

magnetic equator and towards the magnetic east on the southern side. The meridional currents flow towards the magnetic equator below $125 \mathrm{~km}$ and away from it above this height, at the equator the currents are flowing upwards. Maeda et al. (1985) have detected a distinct variation in the geomagnetic $D$ component near the dip equator from the NASA Magnetic Field Satellite (MAGSAT) data which recorded vector magnetic field in the dawn-dusk meridional plane. This variation appeared only on the dusk side and on both sides of the dip equator with a negative peak near $8^{\circ} \mathrm{N}$ dip latitude and a positive peak near $8^{\circ} \mathrm{S}$ dip latitude. Langel et al. (1993) have described a comprehensive analyses of MAGSAT data. They found clear dip-latitude organised field variations associated with electrojet and associated meridional currents in the dusk data. They show a variation with longitude apparently associated with the longitudinal variation of the strength of the main field in the $E$ region.

It is to be remembered that the Magsat operated during fairly active period of solar activity sunspot number being about. During active solar activity period the electrojet current decreases very slowly after sunset (Rastogi and Iyer, 1976) and thus the electric field

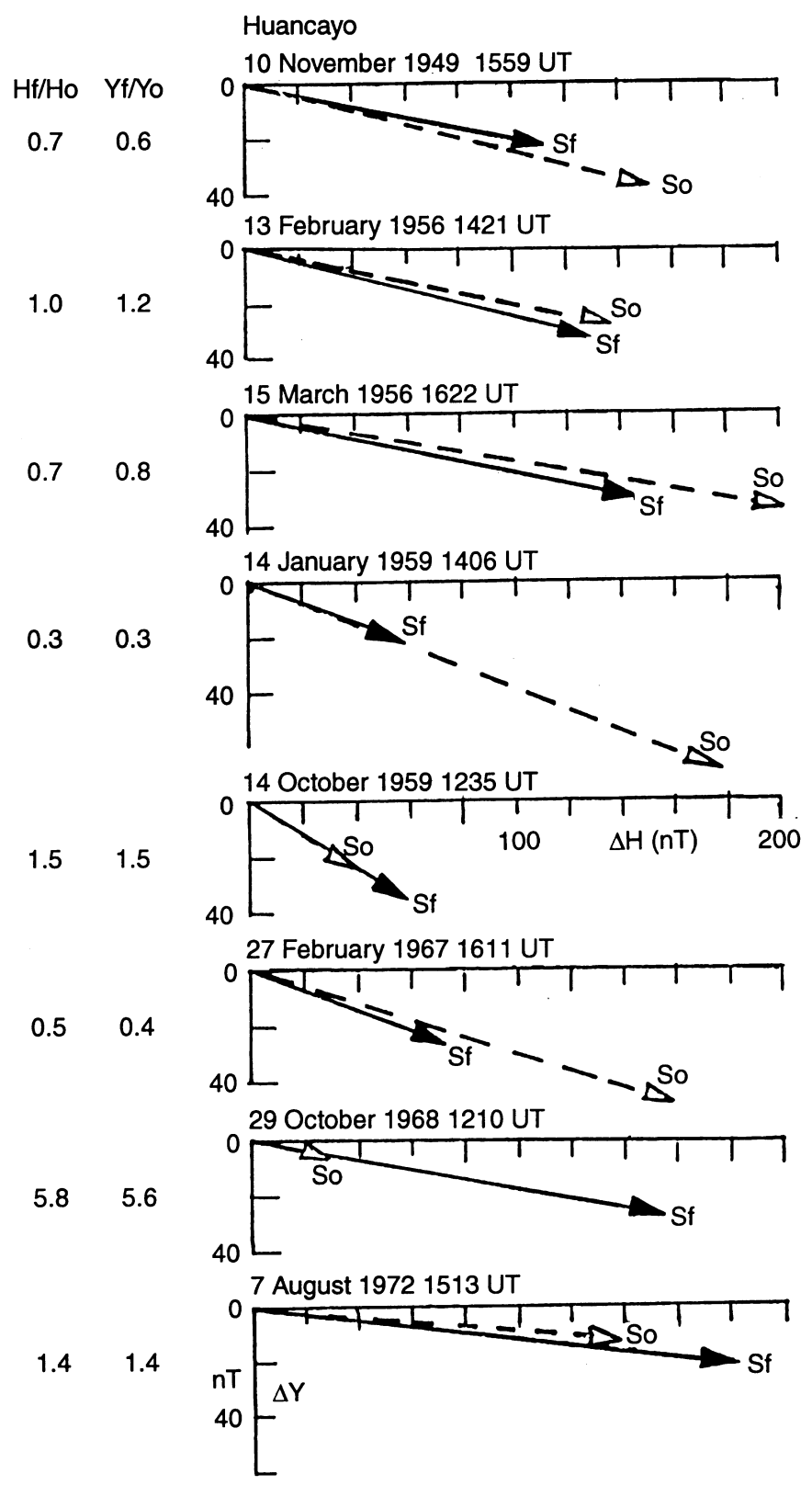

Fig. 12. Current vectors due to solar flare and pre flare $\mathrm{Sq}$ fields at Huancayo during some of the solar flares

should be eastward during the dusk periods. During the dawn periods of high solar activity years, there exists a condition of counter electrojet and therefore the electric field would be westward on many occasions during dawn period (Rastogi) et al., 1996). These inferences are further evidenced by the almost daily occurrence of spread $\mathrm{F}$ irregularities during the southern solstice months after dusk, which requires an eastward electric field to combine with vertical gradient of the electron density to seed the gradient drift instabilities in the ionosphere (Rastogi, 1980).

The present analyses confirm that as in Indian longitude, the meridional currents at equatorial electrojet stations in American longitudes too flow in the same altitudes as the regular daily zonal electrojet current. A 
sfe during counter electrojet
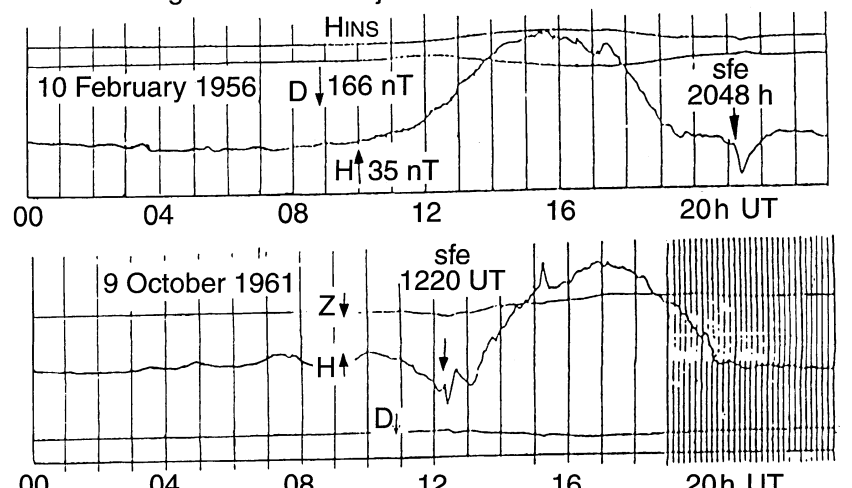$$
00
$$
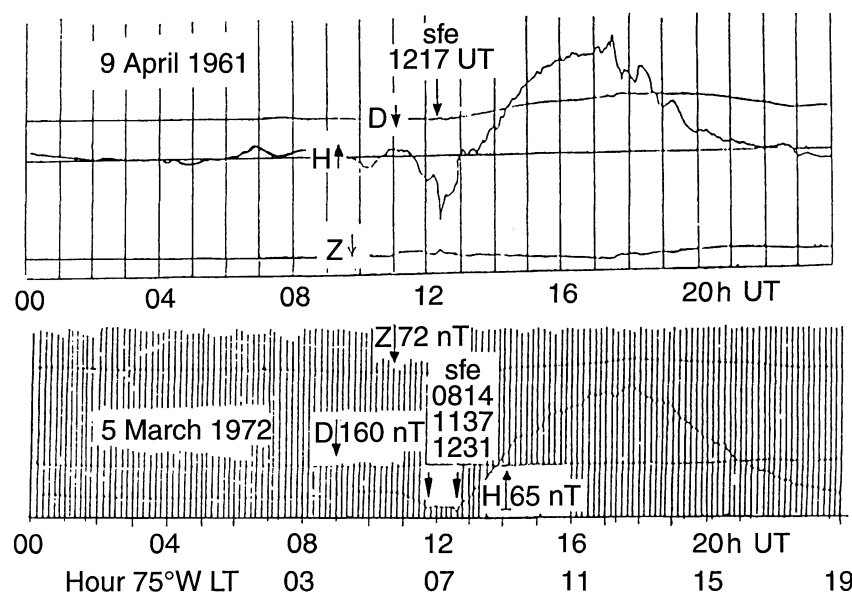

Fig. 13. Magnetograms at Huancayo showing solar flare effects during counter electrojet period

puzzling observation, still to be explained, is the midday maximum of eastward magnetic field at Huancayo in contrast to the midday minimum observed at other electrojet stations.

\section{Conclusions}

1. Along Indian longitudes normal electrojet current (positive $\Delta H$ ) is associated with poleward meridional current (negative $\Delta Y$ ). Along American longitudes the normal electrojet current (positive $\Delta H$ ) is associated with equatorward meridional current (positive $\Delta Y$ ).

2. During counter electrojet periods the meridional current reverses its direction both at Indian as well as American longitudes, with respect to that during eastward electrojet current.

3 . The solar flare during normal electrojet conditions at Huancayo produces positive impulses both in $H$ as well as in $Y$ fields and a negative impulse in $Z$ field.

4. During counter electrojet period, a solar flare produces negative impulses in both $H$ and $Y$ fields and a positive impulse in $Z$ field.

5. At Indian or in American longitudes the solar flare effect is just the enhancement of the existing zonal and meridional electrojet currents just at the time of flare onset.
Acknowledgements. Thanks are due to WDC-A for STP at Boulder for supplying the relevant data under the Arther Day Grant offered to the author jointly with A.H. Shapley. Thanks are due to the Gujarat University and Physical Research Laboratory for the facilities for conducting the investigations. The author is indebted to Indian National Science Academy for selecting him as Senior Scientist and providing him with financial assistance. Thanks are also due to the referees for their suggestions.

Topical Editor D. Alcayde' thanks J.H.A. Sobral and another referee for their help in evaluating this paper.

\section{References}

Broun, J. A., Trivandrum Magnetic Observations Vol I, Henry S. King and Co. London 1874.

Chapman, S., The equatorial electrojet as detected from the abnormal electric current distribution above Huancayo, Peru and elsewhere, Arch. Meteorol. Geophys. Bioclimatol. A4, 368390, 1951.

Chapman, S, and J. Bartels, Geomagnetism Vol I, Clarendon Press Oxford 1940.

Chapman, S, and K. S. Rajarao, The $H$ and $Z$ variations along and near the equatorial electrojet in Indian, Africa and the Pacific. $J$. Atmos. Terrs. Phys. 27, 559-581, 1965.

Egedal, J., The magnetic diurnal variation of the horizontal force near the magnetic equator, Terr. Magn. Atmos. Electr. 52, 449451, 1947.

Forbush, S. E., and M. Casaverde, Equatorial electrojet in Peru, C.I.W. Publishers 620 Washington D. C. 1961.

Langel, R. A., M. Puruoker, and M. Rajaram, The equatorial electrojet and associated currents as seen in Magsat data, $J$. Atmos. Terr. Phys. 55, 1233-1269, 1993.

McNish, A. G., Bulletin 10, Int. Assoc. Terr. Magn. Electr., pp 271280, 1937.

Maeda, H., T. Kamei, T. Iyemori, and T. Araki, Geomagnetic perturbation at low latitudes observed by Magsat, J. Geophys. Res., 90, 2481-2486, 1985.

Malin, S. R. C, and J. C, Gupta. The Sq current system during the international Geophysical year, Geophys. J. R. Astron. Soc., 49, 515-529, 1977.

Matsushita, S., and H. Maeda On the geomagnetic solar quiet daily variation field during the IGY, J. Geophys. Res., 70, 2535-2558, 1965.

Nagata, T., Characteristics of the solar flare effect ( $\mathrm{Sq}$ a) on geomagnetic field at Huancayo (Peru) and at Kakioka (Japan), J. Geophys. Res., 57, 1-14, 1952.

Parkinson, W. D., An analysis of the geomagnetic diurnal variation during the International Geophysical year, Beitr. Geophys., 80, 199-232, 1971.

Patil, A., B. R. Arora, and R. G. Rastogi, Daily variations of the geomagnetic field near the focus of Sq current system in Indian longitude, Proc. Ind. Acad. Sci., 92(3), 239-245 (1983).

Price, A. T., and D. J. Stone, The quiet day magnetic variations during the IGY, Ann. IGY 35 Pt III, 64-249, 1964.

Rastogi, R. G., Seasonal variation of equatorial spread $\mathrm{F}$ in the American and Indian zones, J. Geophys. Res., 85 (A2). 722-725, 1980.

Rastogi, R. G., Longitudinal variation in the equatorial electrojet, J. Atmos. Terr. Phys., 24, 1031-1040, 1992.

Rastogi, R. G., Remarkable solar cycle, and seasonal dependence of the diurnal geomagnetic D-variation at equatorial electrojet station kodaikanal, J. Geomagn. Geoelectr., 45, 657-668 (1993).

Rastogi, R. G., Solar flare effects on zonal and meridional currents at the equatorial electrojet stations, Annamalainagar, J. Atmos. Terr. Phys., 58, 1413-1420, 1996.

Rastogi, R. G., and K. N. Iyer, Quiet day variation of geomagnetic $\mathrm{H}$ field at low latitudes, J. Geomagn. Geoelectr., 28, 461-478, 1976. 
Rastogi. R. G., and S. D. Verma, Abnormal reversals of meridional and zonal equatorial electrojet current, Ind. J. Rad. Space. Phys., 23, 387-392 (1994).

Rastogi, R.G., H. Chandra, and M. E. James, Nocturnal variations of geomagnetic horizontal field at equatorial stations, Geophys. Res. Lett., 23, 2601-2604, 1996.

Rastogi, R. G., and R. J. Stening, Geomagnetic variations in $H, D$ and $Z$ at equatorial latitudes, (submitted to Annales Geophysicae, 1997).
Suguira, M. and J. C. Cain, A model equatorial electrojet, $J$. Geophys. Res. 71, 1869-1877, 1966.

Suzuki, A., A new analysis of the goemagnetic Sq field, J. Geomagn. Geoelectr., 25, 259-280, 1973.

Untiedt, J., A model of the equatorial electrojet involving meridional currents, J. Geophys. Res., 72, 5799-5810, 1967. 